\title{
Produção textual em ambientes virtuais na disciplina de língua inglesa
}

Ana Teresinha Elicker ${ }^{1}$ Universidade Feevale anaelicker@feevale.br

Lucas Souza Santos ${ }^{2}$ Universidade Feevale lucasefi94@gmail.com

Viviane Cristina De Mattos Battistello ${ }^{3}$ Universidade Feevale

vivimattos@feevale.br

DOI: https://doi.org/10.21158/2357514x.v8.n1.2020.2743

Cómo citar este artículo: Elicker, A. T.; Souza Santos, L.; De Mattos Battistello, V. C. (2020). Produção textual em ambientes virtuais na disciplina de língua inglesa. Revista Virtu@lmente, 8(1), 61-76. DOI: https://doi.org/10.21158/2357514x.v8.n1.2020.2743

Fecha de recepción: 02 de agosto de 2020

Fecha de aprobación: 13 de septiembre de 2020

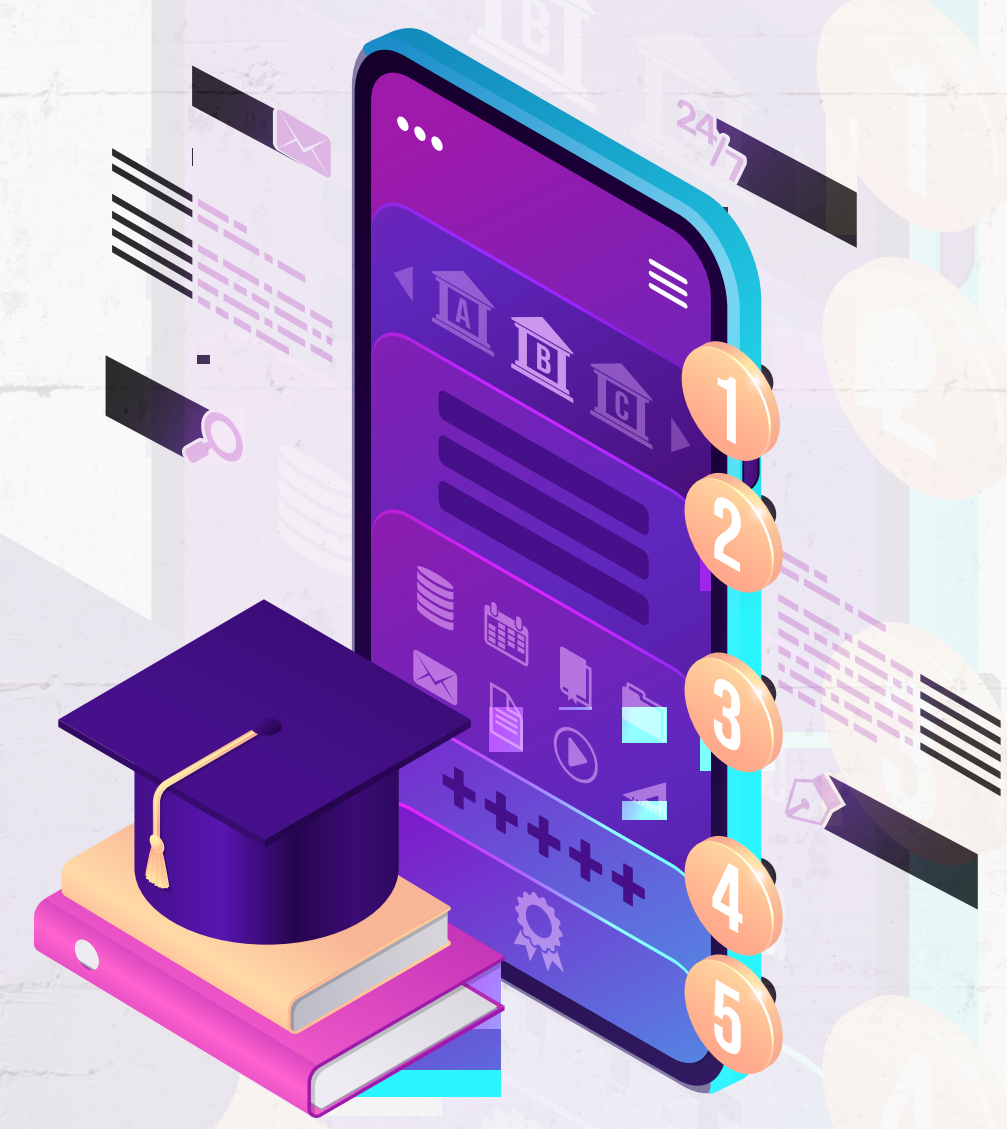

${ }_{1}^{1}$ Doutoranda do programa de Pós-Graduação em Diversidade Cultural e Inclusão Social pela Universidade Feevale. Escritora e Professora Graduada em em Letras - Português/Inglês e literaturas pelo Centro Universitário Feevale. Especialização em EJA, pela PUCRS e em gestão escolar, pela UFGRS. ORCID: https://orcid.org/0000-0003-1432-6506

2 Bacharelado em educação física (educação) - UNICNEC. Pós graduação lato sensu em educação básica profissional (educação) - FRS Campus Osório. Licenciatura em educação física (educação) UNIASSELVI. Pós graduação stricto sensu em diversidade cultural e inclusão social (educação) - Universidade Feevale. ORCID: https://orcid.org/0000-0002-1023-8480

${ }^{3}$ Doutoranda do programa de Pós-Graduação em Diversidade Cultural e Inclusão Social pela Universidade Feevale Mestrado profissional em letras - Universidade Feevale. ORCID: https://orcid.org/0000-0002-0482-8927 


\section{RESUMO}

O artigo apresenta uma prática pedagógica que propõe a compreensão e produção de textos na disciplina de Língua Inglesa, em ambientes virtuais, com a utilização de aplicativos para smartphones, de forma interativa, entre os alunos da Escola Estadual Comendador Albino Souza Cruz, na cidade de Rolante, no sul do Brasil. Para o desenvolvimento das atividades, questionou-se como construir textos utilizando aplicativos de dispositivos móveis e ao mesmo tempo proporcionar oportunidades de aprendizagem. Através da metodologia da pesquisa-ação e como objetivo geral, apresentar uma proposta de compreensão e produção textual, em benefício do desenvolvimento de habilidades comunicativas de linguagem. Os resultados mostraram que a produção de texto digital em plataforma compartilhada contribui para a formação cooperativa, pois à medida que um aluno aprende, o outro visualiza o texto e também se apropria desse novo conhecimento. Concluímos que é necessário centrar a discussão na aprendizagem dirigida às pedagogias emergentes e no impacto que estas podem ter no desenvolvimento de habilidades para o século XXI.

Palavras-chave: produção textual; ambientes virtuais de aprendizagem; prática pedagógica; dispositivos móveis; formação cooperativa. 


\section{Producción textual en entornos virtuales en la disciplina del idioma inglés}

\section{RESUMEN}

El artículo presenta una práctica pedagógica que propone la comprensión y producción de textos en la disciplina del idioma inglés, en entornos virtuales, con el uso de aplicaciones para teléfonos inteligentes, de manera interactiva, entre los alumnos de la Escuela Estatal Comendador Albino Souza Cruz, en la ciudad de Rolante., sur de Brasil. Para el desarrollo de actividades se cuestionó cómo construir textos utilizando las aplicaciones de los dispositivos móviles y al mismo tiempo brindar oportunidades de aprendizaje. A través de la metodología de la investigación-acción y como objetivo general presentar una propuesta de comprensión y producción textual, en beneficio del desarrollo de las habilidades comunicativas del lenguaje. Los resultados mostraron que la producción de texto digital en una plataforma compartida contribuye a la formación cooperativa, porque a medida que uno aprende, el otro visualiza el texto y también se apropia de este nuevo conocimiento. Concluimos que es necesario centrar la discusión en el aprendizaje dirigido a las pedagogías emergentes y el impacto que estas pueden tener en el desarrollo de habilidades para el siglo XXI..

Palabras clave: producción textual; entornos virtuales de aprendizaje; práctica pedagógica; dispositivos móviles; formación cooperativa. 


\section{Textual production in virtual environments in the English language discipline}

\section{ABSTRACT}

This article presents a pedagogical practice that proposes the comprehension and production of texts in the English language discipline, in virtual environments, with the use of applications for smartphones, in an interactive way, among the students of the State School Comendador Albino Souza Cruz, in the city of Rolante, south Brazil. For the development of activities, we questioned how to build texts and at the same time provide learning opportunities using the applications for mobile devices. The study is carried out by means of the action research methodology, with the general objective of presenting a proposal for understanding and producing text, in benefit of the development of language communication skills. The results showed that the production of digital text on a shared platform contributes to cooperative training, because as one learns, the other visualizes the text and also makes use of this new knowledge. We conclude that it is necessary to focus the discussion on the learning that is aimed at emerging pedagogies, and on the impact that these can have on the development of skills for the 21 st century.

Keywords: text production; virtual learning environments; pedagogical practice; mobile devices; cooperative training. 


\section{Production écrite virtuelle en langue anglaise}

\section{RÉSUMÉ}

Cet article présente une pédagogie compréhensive en environnement d'apprentissage non présentiel, mise en place par l'école Comendador Albino Souza Cruz, de la ville de Rolante, au sud du Brésil, pour la production de textes en langue anglaise au travers de l'utilisation, par les étudiants, d'applications interactives pour smartphones. Ces activités consistent en la création de textes à l'aide d'applications mobiles qui permettent, de manière simultanée d'offrir des opportunités d'apprentissage. La méthodologie utilisée, de type investigation-action, a pour objectif de proposer une compréhension et une production de textes au profit du développement des compétences communicatives et langagières. Les résultats ont montré que la production de textes numériques, sur une plateforme collaborative, contribue à la formation coopérative, car lorsqu'un étudiant apprend, l'autre visualise le texte et s'approprie simultanément ces nouvelles connaissances. Nous concluerons qu'il est nécessaire de recentrer la discussion sur l'apprentissage au travers des pédagogies interactives et sur l'impact que celles-ci peuvent avoir sur le développement des compétences.

Mots-clés: production textuelle; environnements d'apprentissage virtuels; pratique pédagogique; appareils mobiles; formation coopérative. 


\section{Introdução}

A cultura digital tem promovido mudanças sociais significativas no contexto educacional, como por exemplo, a inserção das tecnologias como recursos pedagógicos. Isto gerou o questionamento sobre como construir -elaborar- textos usando os aplicativos dos dispositivos móveis e ao mesmo tempo oportunizar o aprendizado em um contexto formal de sala de aula o que, de acordo com Elicker e Barbosa (2020), amplia a comunicação na cultura digital.

Com base na metodologia de pesquisa-ação, que consiste no acompanhamento sistemático do objeto de estudo, este texto visa desenvolver uma proposta pedagógica, com atividades interativas para a compreensão e a produção de textos na disciplina língua inglesa, em ambientes virtuais, com o uso de aplicativos para smartphones. Através de pesquisa bibliográfica, em abordagens de ensino com recursos tecnológicos, com a fundamentação teórica e com autores de referência, buscou-se os conceitos de Multiletramento (Rojo, 2013), Abordagem interativa (Lemos e Lévy, 2010), Sistemas de Colaborativo (Nicolaci da Costa e Pimentel, 2011), Ecossistemas digitais de aprendizagem (Moreira e Porto, 2017), e abordagens híbridas em (Elicker et al. 2019)

Os resultados apresentaram a rapidez do letramento digital, a facilidade de mobilidade de troca de informações e a colaboração na elaboração dos textos, ampliando o conhecimento do idioma. Assim, observou-se que a turma $A$, que desenvolveu a atividade com o uso das tecnologias, finalizou o conteúdo programático quatro horas antes da turma $B$, que teve abordagem sem recursos digitais. Houve maior interação e troca de informações na turma $A$ e, ao mesmo tempo que ampliava o conhecimento do conteúdo, também aprendia novos recursos para desenvolver as tarefas. Nessa perspectiva, a estrutura do artigo está organizada em quatro seções distintas: a produção de texto na cultura digital na perspectiva dos Sistemas Colaborativos; a metodologia que descreve o desenvolvimento da e-atividade; os resultados e discussão da e-atividade e, por último, as considerações finais.

\section{A produção de texto na cultura digital}

Atualmente, as mensagens e informações são instantâneas e globalizadas pela comunicação, fato que exige que os usuários apresentem um desenvolvimento satisfatório sobre o manuseio dos recursos multimidiáticos, que são geralmente gratuitos. Inúmeros aplicativos podem ser instalados em dispositivos móveis, como celulares ou tablets, ou ainda usados de maneira online. Nesse sentido, Elicker e Barbosa (2020) corroboram os estudos sobre as informações disponíveis em links, páginas de sites, através de textos midiáticos, abrindo um leque de multi leituras e, portanto, confirmando a necessidade de multiletramentos.

O conceito de multiletramentos aponta para dois tipos específicos e importantes de multiplicidade: a cultural das populações e a semiótica de constituição dos textos por meio dos quais ela informa e comunica (Gomes, 2017). Os textos 
digitais possuem características híbridas, como se percebe na pesquisa, e dessa forma o melhor lugar para eles existirem é 'nas nuvens ${ }^{4 \prime}$ e a melhor maneira de se apresentarem é na estrutura ou formato de redes — hipertextos, hipermídias(Rojo, 2013).

Diante do exposto, no ambiente de sala de aula é necessário o olhar para a leitura e a escrita, além de um direcionamento às práticas pedagógicas interativas, pois, para «além da cultura do impresso - ou da palavra escrita-, que deve continuar tendo centralidade na educação escolar, é preciso considerar a cultura digital, os multiletramentos, os novos letramentos entre outras denominações que procuram designar novas práticas sociais e de linguagem» (Ministério Da Educação, 2018a, p.478). Considera-se ainda que:

a cultura digital tem promovido mudanças sociais significativas nas sociedades contemporâneas. Em decorrência do avanço e da multiplicação das tecnologias de informação e comunicação e do crescente acesso a elas pela maior disponibilidade de computadores, telefones celulares, tablets e afins, os estudantes estão dinamicamente inseridos nessa cultura, não somente como consumidores. Os jovens têm se engajado cada vez mais como protagonistas da cultura digital, envolvendo-se diretamente em novas formas de interação multimidiática e multimodal e de atuação social em rede, que se realizam de modo cada vez mais ágil. Por sua vez, essa cultura também apresenta forte apelo emocional e induz ao imediatismo de respostas e à efemeridade das informações, privilegiando análises superficiais e o uso de imagens e formas de expressão mais sintéticas, diferentes dos modos de dizer e argumentar característicos da vida escolar (Ministério Da Educação, 2018b, p. 60)

De acordo com Elicker (2020a), quanto ao uso das tecnologias o aluno não é um mero consumidor, mas sim um agente interativo. No desenvolvimento das atividades práticas ele interage e produz seus textos utilizando o celular como um recurso pedagógico. Com base nessa realidade escolar permeada pela cultura digital, Rojo $(2013$, p. 13) afirma que «a produção de textos multimodais pode ser vista como uma prática que transcende a proposta tradicional de ensino, como novas formas de competências nestes tempos». De maneira que provoca uma ruptura do modelo clássico de ensino de língua e da gramática normativa, por meio do uso de um novo ambiente de aprendizagem, mais interativo e dinâmico, com novos textos multimodais, com novas mídias, ampliando a capacidade de produção de texto e de leitura crítica, considerando que letramento é sempre letramento em algum gênero.

Nessa perspectiva de produção de texto, o ambiente digital propicia o uso do gênero digital, que se caracteriza como um multitexto e que é composto por texto verbal e não verbal, de maneira híbrida, em dispositivos eletrônicos fáceis de serem manuseados pelos nativos digitais no contexto de sistemas colaborativos, que podem ser explorados no ambiente escolar. 
O sistema colaborativo, é um termo brasileiro utilizado para representar a terminologia em inglês CSCW (Computer Supported Cooperative Work) e groupware. Salienta-se que muitos consideram como sinônimos esses termos e outros preferem reservar a palavra groupware para designar especificamente os sistemas computacionais usados para apoiar o trabalho em grupo, enquanto que a palavra CSCW é utilizada para designar tanto os sistemas (CS) quanto os efeitos psicológicos, sociais e organizacionais do trabalho em grupo (CW). Contudo, ambos os termos cunhados mesmo antes da web, estão relacionados com os sistemas computacionais dando apoio à colaboração (Nicolaci da Costa e Pimentel, 2011).

Existem diferentes ambientes e ferramentas de colaboração online de acesso aberto e/ou gratuito que auxiliam no trabalho colaborativo e caracterizam-se por oferecer situações que envolvem a comunicação, a elaboração e a cooperação entre os participantes, de acordo com Pimentel e Fuks (2011), como por exemplo o Google Docs para a escrita coletiva. Desta forma, a coordenação de um trabalho colaborativo consiste em organizar os membros de um grupo de pessoas para que seus esforços sejam direcionados durante a execução das atividades, além de permitir que as negociações sejam realizadas na ordem e tempo previstos cumprindo seus objetivos e restrições (Fuks et al., 2007).

Em uma perspectiva educacional, a aprendizagem colaborativa tem como benefícios a preparação para a vida em sociedade, o desenvolvimento do espírito crítico e a competência para resolver problemas de grande porte, a partir das contribuições individuais (Castro e Menezes, 2011). Percebe-se, nesta prática que os alunos — nativos digitais - têm habilidades de uso dos textos digitais multimodais disponíveis livremente na web, embora ainda apresentem dificulda- des em identificar quais informações são confiáveis e quais devem ser descartadas, o que os faz visitar diferentes sites em busca de notícias semelhantes e fontes de pesquisa com vínculos a suportes com confiabilidade pública, e buscar se algum jornal conhecido publicou algo sobre o fato pesquisado. Desta forma o professor pode orientá-los em como proceder para verificar a veracidade da informação. $O$ processo de aprendizagem, de acordo com Elicker (2020b, p.1), «exige um movimento contínuo de construção, adaptação e readaptação das informações, tanto do professor quanto do aluno. Para que isso ocorra, o estudante precisa compreender o conteúdo para se apropriar e, a partir daí, estabelecer relações e atribuir significados».

Desse modo, o uso do texto digital em plataforma compartilhada, como do Google Docs, contribui para formação cooperativa, pois na medida que um aprende, o outro visualiza o texto e se apropria também deste novo saber. Existe, portanto, uma necessidade de focar a discussão em uma aprendizagem voltada para as pedagogias emergentes, e no impacto que estas podem ter no desenvolvimento de competências para o século 21. Assim, se neste contexto aceita-se que as tecnologias - audiovisuais, multimédia, entre outras- são ferramentas inovadoras para a criação de «ecossistemas digitais de aprendizagem dinâmicos, e que as ferramentas da web social configuram novos ambientes educativos, então é crucial reconhecer a necessidade do processo ser sustentado por modelos que permitam produzir as competências hoje necessárias ao sucesso das organizações» (Moreira, 2017, p. 17).

Outro fator é em relação à participação dos alunos: na cultura digital contemplando os novos multiletramentos, como a escrita digital, que acontece de forma tranquila «nàs diversas práticas sociais permeadas/constituídas pela 
oralidade, pela escrita e por outras linguagens» (Ministério Da Educação, 2018b, p. 66). Nesse contexto, observa-se a familiaridade dos alunos com o uso de aplicativos, visto que existem vários deles para dispositivos móveis, como tablets e smartphones, que são interessantes para o registro do processo de aprendizagem, sendo que «os aplicativos móveis podem ser de três diferentes tipos: nativos, web e híbridos» (Scherer-Bassani e da Silva-Nunes, 2016, p.52).

As mesmas autoras explicam que "aplicativos nativos são aqueles que podem ser instalados no dispositivo móvel via loja de aplicativos [...] e podem ser utilizados sem conexão à internet, e os aplicativos web precisam de acesso à internet [ou no caso os aplicativos híbridos, que] e possuem características mistas, são parcialmente nativos e parcialmente web» SchererBassani e da Silva-Nunes, 2016, p. 52).

Ademais, é relevante observar o perfil de aluno nessa prática, que se apresenta como sendo responsável pelo processo, além de desenvolver diferentes funções ao longo das atividades, pois ele precisa buscar a informação, se apropriar do conhecimento, compartilhar e reconstruir quantas vezes forem necessárias para socializar com os demais colegas. Há uma relação dialógica entre os textos e os alunos no transitar entre esses diferentes meios informativos, pois eles estabelecem «relações de intertextualidade e interdiscursividade que permitem a identificação e compreensão dos diferentes posicionamentos e/ou perspectivas em jogo» (Ministério Da Educação, 2018b, p. 72). Nesse processo, o professor exerce a função de mediador pois auxilia na busca de informações, conectando os conteúdos da disciplina e o acesso aos seus elementos, utilizando dispositivos que possibilitam sua prática pedagógica.

\section{Desenvolvimento da e-atividade: metodologia}

O estudo, caracteriza-se por ser de cunho qualitativo. Realizou como pesquisa-ação, a qual estimula a participação das pessoas envolvidas na pesquisa e abre o seu universo de respostas, passando pelas condições de trabalho e vida dos envolvidos (Thiollent, 1988). A pesquisa-ação visa através das novas informações, a melhoria de produções de conhecimentos, ensino-aprendizagens e de resolução de situações problemas referentes à prática proposta.

A coleta de dados se constituiu a partir de um projeto de e-atividades, que englobou a produção textual em ambientes virtual, com a duração de 4 encontros de duas horas cada, aplicado nas aulas de Língua Inglesa, no meses de fevereiro a março/2020. Estes encontros se organizaram da seguinte maneira:

Quadro 1. Resumo dos quatro encontros

\begin{tabular}{|c|l|}
\hline Encontro & \multicolumn{1}{c|}{ Atividade } \\
\hline 1 & $\begin{array}{l}\text { Diálogo entre professora e alunos, de modo a con- } \\
\text { hecer os grupos, bem como, seus saberes e desejos; }\end{array}$ \\
\hline 2 & $\begin{array}{l}\text { Definição de quais recursos midiáticos e tecnologias } \\
\text { seriam utilizados e quais assuntos seriam abordados } \\
\text { na produção do projeto; }\end{array}$ \\
\hline 3 & $\begin{array}{l}\text { Busca da apropriação das informações e criação de } \\
\text { novas informações com base nos recursos; }\end{array}$ \\
\hline 4 & $\begin{array}{l}\text { Compartilhamento de ideias com os colegas para } \\
\text { efetivar a autoavaliação e divulgação dos resultados. }\end{array}$ \\
\hline
\end{tabular}

Fonte. Organizado pelos autores 
Os participantes da pesquisa foram: os pesquisadores, a professora de inglês e os alunos de uma turma mista de adolescentes de 16 e 17 anos, do terceiro ano do Ensino Médio, em uma escola pública do sul do Brasil. A turma escolhida para realizar a prática era composta por 23 alunos e as aulas aconteceram no turno da manhã. Não houve critério específico para escolha da turma, uma vez que os próprios alunos manifestaram o desejo de usarem os recursos tecnológicos a partir do celular para o aprendizado. De acordo com Elicker (2020a, p. 1), «no atual momento em que vivemos, há várias plataformas e aplicativos que beneficiam o ensino a distância de forma bem simples e acessível. Plataformas e aplicativos que podem, inclusive, ser utilizados por meio dos celulares».

\section{Resultados da e-atividade}

A proposta de produção de textos em espaços virtuais, com uso dos smartphones, foi apresentada aos alunos, após conhecê-los e perceber o interesse deles em desenvolver as atividades nos ambientes virtuais. Tendo em vista que:

um sistema colaborativo não deve se restringir ao comando e controle da realização das tarefas, como é a forma típica de trabalho na linha de montagem industrial clássica. Um sistema mais adequado à nova sociedade deve ser concebido para ser um espaço a ser habitado. Deve ser condizente com as necessidades das novas gerações, formado por jovens que desejam colaborar, interagir e compartilhar, sem uma hierarquia rígida, que tenha flexibilidade de horário e lugar, que favoreça a criação e a informalidade. (Nicolaci da Costa e Pimentel, 2011, p.13)

Ao desenvolver as atividades, optou-se por oportunizar a participação de todos os alunos, de maneira que fossem parte ativa de todo o processo. Desta forma, opinaram e escolheram o assunto de estudo, sendo o celular utilizado como recurso pedagógico.

No primeiro encontro, houve a aproximação pela fala e busca da empatia para criar vínculo. Assim, ocorreu um levantamento e anotações sobre o que os alunos sabiam e o que mais gostariam de saber. Em seguida, organizou-se a primeira e-atividade com um roteiro. Após a criação de um documento no Google Drive ${ }^{5}$, os alunos deveriam inserir seus nomes e endereço de e-mail. Depois, os alunos tinham como tarefa a criação de um quadro de apresentação pessoal, no idioma inglês, que seria realizado em casa. Essa apresentação pessoal incluía: inserir uma foto, dizer o nome, idade, indicar o lugar de moradia e de trabalho, o que gostava, comida preferida, esporte favorito, que curso desejava fazer depois do ensino médio e outras informações que o aluno considerasse relevante.

\footnotetext{
${ }_{5}^{5}$ «O Google Docs, é um pacote de aplicativos do Google baseado em AJAX. As ferramentas do Google Docs funcionam de forma síncrona e assíncrona, portanto, on-line para acessar dados em nuvens éf-los online, diretamente no browser de desktops ou aplicativos de dispositivos móveis do Android e Mac. Os aplicativos são compatíveis com o OpenOffice.org/BrOffice.org. KOffice e Microsoft Office, e atualmente compõem-se de um processador de texto, um editor de apresentações, um editor de planilhas e um editor de formulários». Site oficial, 2019.
} 
Na segunda tarefa, os alunos foram orientados a organizarse em pequenos grupos, de livre escolha, e como tarefa: inserir as atividades no documento do Google Docs, na plataforma do Google Drive. A tarefa consistiu em: uma foto e texto em inglês. Para desenvolver a tarefa a turma se organizou em grupos, tiveram tempo para escolher um nome e tirar fotos do grupo. O texto em inglês deveria vir com uma breve apresentação do grupo bem como a explicação da escolha do nome.

Quadro 2. Com a primeira e segunda atividade de Produção textual na Aula de Inglês

\begin{tabular}{|c|c|c|}
\hline $\begin{array}{c}\text { First task: } \\
\text { Who are you? } \\
\text { white }\end{array}$ & $\begin{array}{l}\text { My names is N.D. I am seven- } \\
\text { teen years old, I am daughter } \\
\text { of L. D. and T.S, I live near the } \\
\text { CTG, my boyfriend is T. M. } \\
\text { Job at the coffee three stars } \\
\text { center. My taste of to know } \\
\text { new places, my dream is to } \\
\text { me to form in quiropraxia, tra- } \\
\text { vel the world and get married. }\end{array}$ \\
\hline $\begin{array}{l}\text { Second task: } \\
\text { Introduce the } \\
\text { study group. }\end{array}$ & $\begin{array}{l}\text { We grow together - We put } \\
\text { this name because we belie- } \\
\text { ve and we can grow much } \\
\text { like a group, and participants } \\
\text { is G., K., M., R. and P. we } \\
\text { study at school Souza Cruz in } \\
\text { class 311. }\end{array}$ \\
\hline
\end{tabular}

Fonte. Arquivo pessoal da professora que aplicou a pesquisa.
Na terceira tarefa cada grupo deveria fazer um texto sobre as características de um professor e postar utilizando um $Q R$ code. Os alunos escolheram em conjunto e definiram que seria importante todos escolherem um professor e escrever um parágrafo apresentando e enaltecendo algumas qualidades do professor escolhido. Cabe salientar aqui que entre a segunda e terceira aula houve mais comentários a respeito da tradução dos textos.

Na quarta tarefa, cada grupo deveria fazer a autoavaliação por meio de palavras que representassem a participação nas e-atividades. Para a tarefa de «nuvem de palavra», os alunos deveriam utilizar o site www.mentimenter.com ${ }^{6}$. A fim de ampliar conhecimentos em inglês, cada aluno deveria se apresentar e apresentar outra pessoa, com riquezas de detalhes.

Quadro 3. Autoavaliativo das e-atividades

\begin{tabular}{|c|c|c|}
\hline $\begin{array}{l}\text { Third Task: Write a } \\
\text { text about a teacher } \\
\text { and post in QRcode }\end{array}$ & $\begin{array}{c}\text { Group: } \\
\text { Fantastic Quartet }\end{array}$ & 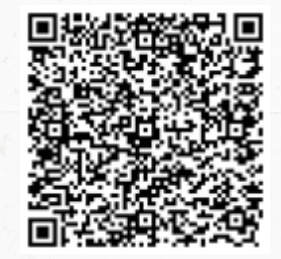 \\
\hline $\begin{array}{c}\text { Fourth class: } \\
\text { self-examination } \\
\text { with significant } \\
\text { words, http://www. } \\
\text { mentimeter.com/ }\end{array}$ & 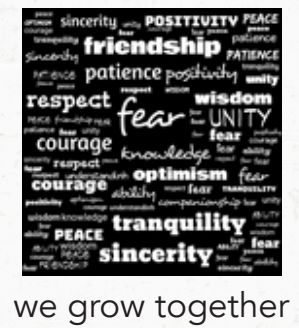 & 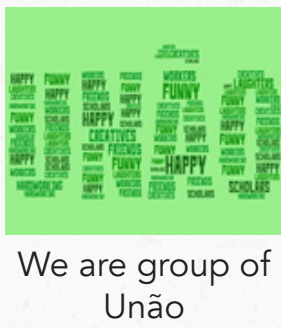 \\
\hline
\end{tabular}

Fonte. Arquivo pessoal da professora que aplicou a pesquisa.

${ }^{6}$ É uma plataforma que cria apresentações e reuniões interativas, como uma nuvem de palavras, onde quer que esteja. Assim, é possível obter informações em tempo real de equipes remotas e alunos online com pesquisas ao vivo, questionários, nuvens de palavras, perguntas, respostas e muito mais. De forma que a diversidade de tipos de questões disponíveis possibilita a dinamização de diferentes tipos de interação com a plateia/turma. 


\section{Discussão da e-atividade}

Ao analisar de forma comparativa, com as demais turmas, os resultados obtidos para este projeto, pode-se constatar, através do retorno das tarefas de acordo com registros e informações da professora pesquisadora, que os alunos desenvolveram maior autonomia e abertura para a criatividade, vinculando-se ao seu processo de ensino-aprendizagem.

Essa constatação vai ao encontro do que é proposto pela Base Nacional Comum Curricular (BNCC), em relação a buscar meios para que os alunos sejam capazes de «compreender e utilizar tecnologias digitais de informação e comunicação de forma crítica, significativa, reflexiva e ética nas diversas práticas sociais, para se comunicar por meio das diferentes linguagens e mídias, produzir conhecimentos, resolver problemas e desenvolver projetos autorais e coletivos» Ministério Da Educação, 2018a, p. 64).

Fator importante a se destacar foi o da motivação, pois segundo registros da professora, percebeuse que os alunos estavam entusiasmados com a possibilidade de realizar as tarefas utilizando os recursos digitais e uma prática envolvendo o coletivo. Salientase que a escrita digital acontece nos dispositivos móveis, é rápida, concisa, abreviada e com uma gama enorme de imagens, como os emojis, que são utilizados para a comunicação dos usuários, inclusive substituindo palavras. Sem uma estrutura pedagógica que motive o aluno «haveria uma mudança no suporte utilizado para as práticas de leitura e escrita, mas não uma alteração nas estratégias desenvolvidas para a aprendizagem dos alunos» (Dos Santos, 2018 , p. 202). O processo de interação entre sujeitosconteúdos-tecnologias tem que estar intimamente ligado.

Percebese também que houve um aprimoramento no que tange ao trabalho em grupo, pois, no segundo encontro os alunos foram orientados a se reunir em grupos espontâneos e criar um nome para a equipe. A tarefa foi postar uma foto, apresentar o grupo explicando a escolha do nome. Esta tarefa foi concluída em sala de aula pela maioria dos alunos, e para os que não conseguiram concluir em aula, foi dada a possibilidade de inseri-la posteriormente no Google Drive, sem que isso causasse prejuízo ao seu processo de aprendizagem. Isto poderia, no entanto, afetar os indicadores utilizados no processo de autoavaliação.

Vê-se que competências inter e intrapessoais foram desenvolvidas nesta etapa, como por exemplo: a interação em grupo, escuta dos colegas, tomada de decisão em grupo, entre outros. Além disso, em um dos grupos havia um aluno com necessidades especiais, que foi logo acolhido. O aluno é cadeirante e apresenta déficit cognitivo leve. Ele possui celular e conseguiu desenvolver as tarefas de forma participativa com os colegas do grupo, sentindo-se pertencente e acolhido pela turma. Partindo disso, observa-se que "o letramento digital dos alunos de modo dinâmico, [traz] a possibilidade de um ensino que dialoga e se reflete na emancipação dos nossos alunos para uma formação cidadã» (Reis e de Carvalho-Lima, p. 30, 2019). 
No quarto encontro, cada grupo teria que escolher um professor e escrever um parágrafo falando por que «ele era o melhor professor» na opinião do grupo. Posteriormente, deveriam criar um $Q R$ code e postar apenas o código no documento. Os alunos com muita facilidade pesquisaram no site de busca do Google como criar o código de QR code, e em instantes já estavam com a tarefa pronta e compartilhando com os demais colegas. Cada grupo buscou diferentes aplicativos para executar essa atividade. Um dos grupos comentou sobre como foi o processo de busca.

Primeiramente nós escolhemos o professor, fizemos um texto sobre ele e traduzimos para o inglês. Depois procuramos vários sites e encontramos um bom e aí fizemos o $Q R$ code. Quando ficou pronto, nós testamos e quando vimos que estava certo colocamos no documento (Grupo União)[sic].

Acerca do uso do código $Q R$ code é relevante salientar que está presente no cotidiano de todos, seja nos telejornais, propagandas, livros didáticos entre outros usos. Atualmente os celulares/smartphones mais atuais, possuem softwares de leitura integrados e, portanto, se faz necessário que o aluno também aprenda a criar outros materiais utilizando essa ferramenta. A tarefa foi concluída em aula e compartilhada com os demais, corroborando a importância de apresentar aos alunos novos softwares. O estudo feito por Pozzo (2020) ilustra exemplos referentes a um curso ministrado em uma universidade argentina, em fase de planejamento. Nesse, a autora propõe o incentivo aos professores na exploração de ambientes digitais, dando-lhes diretrizes para uma melhor integração entre educação e tecnologias, sendo a pluralidade de ferramentas e meios, algo em destaque. Assim, a produção de escrita, mas também manuseio de códigos $Q R$ code amplifica e pluraliza a prática.

Embora o foco tenha sido a produção da escrita, o trabalho não se deteve apenas nesse desenvolvimento. No terceiro encontro os alunos apresentaram os textos por meio de slides no aplicativo Power point_-alguns com comentários-e foram fazendo as modificações de acordo com as necessidades. Parece simples, porém o ato de expor ideias é fundamental na construção da aprendizagem. Consoante ao estudo realizado por Oliveira (2014) a autora relatou uma experiência de tutoria online de língua portuguesa. Assim como observou-se em nossa pesquisa, esse artigo também apontou melhorias no letramento digital e na autonomia dos alunos, e ao final em uma produção colaborativa foi produzido um artigo acadêmico pelos alunos, a ser apresentado em um congresso online, mostrando assim a importância da apresentação de um produto pelos aluno.

Ao final, os alunos realizaram a autoavaliação de forma criativa, por meio da criação de uma nuvem de palavras, ou seja, de maneira concisa representaram a participação de cada um durante as e-atividades, utilizando o site do mentimeter. com. Observa-se que o desenvolvimento das e-atividades estratégia didática- evidenciou que o processo «apontou no sentido de conseguir que o grupo se tornasse uma verdadeira comunidade virtual de aprendizagem interativa, colaborativa e investigativa» (Moreira, 2018, p. 12). Salienta-se, conforme concepção de Lemos e Lévy que, 
não se trata de usar as tecnologias a qualquer custo, mas sim de acompanhar consciente e deliberadamente uma mudança de civilização que questiona profundamente as formas institucionais, as mentalidades e a cultura dos sistemas educacionais tradicionais e, sobretudo os papéis de professor e aluno. (2010, p. 174)

Diante disso, o professor deve ter estratégias para aproveitar esses conhecimentos, para chamar a atenção de seus alunos, motivando e inovando o processo de ensinoaprendizagem, como por exemplo, na produção de materiais mediada pelo uso de aplicativos para ler e produzir textos, verbais ou não-verbais de maneira híbrida nos ambiente virtuais.

\section{Conclusão}

O presente trabalho apresenta indícios de que a interação favorece o desenvolvimento da compreensão e da produção de textos na disciplina de Língua Inglesa, em ambientes virtuais. Oferece um caminho de renovação das práticas pedagógicas, e assim, possibilita ao aluno o desenvolvimento da autonomia, da autoria e da colaboração entre os colegas. $\bigcirc$ uso da tecnologia potencializa o processo de aprendizagem, uma vez que os alunos têm em mãos recursos que os aproximam das informações.

Percebeu-se que o contato com o ambiente digital fez com que os alunos aprendessem a utilizar as ferramentas, como por exemplo, o documento do Google Drive, o código $Q R$ code e o aplicativo de criação de nuvem de palavras - mentimenter-, que se apresentam como excelentes recursos pedagógicos. Desta forma, se trazem melhorias significativas para a sala de aula, com critério e planejamento, possibilitando a fomentação e o incremento de modelos de e-atividades, ou seja, as atividades interativas com uso da tecnologia digital, que visam despertar o interesse, a motivação e o sentimento de desafio da cultura digital entre os alunos.

Durante a realização da prática, observou-se um grande engajamento dos alunos, o que proporciona uma maior equidade no ambiente de aprendizagem. A inserção do professor, no contexto do ensino híbrido gera um profissional reflexivo, que busca «intervenções efetivas», através de um novo posicionamento e atuação contínuos na díade professoraluno, pois as atividades são colaborativas, oportunizando a troca de conhecimentos e igualando oportunidades de aprendizagem. O professor se distancia de replicar o modelo tradicional, com aulas apenas expositivas, reproduzindo informações que muitas vezes não contribuem para a construção coletiva do conhecimento.

Nesse sentido, à medida que o professor se insere no universo plural de sala de aula e no mundo singular do processo de aprendizado dos alunos, a inclusão e a equidade acontecem de forma natural. Percebe-se que cada um é único em seus entendimentos e todos têm a compartilhar, seja auxiliando o colega ou sendo auxiliado, promovendo a diversidade de conhecimento. Assim, os alunos foram orientados a se auxiliarem mutuamente e de maneira inclusiva, buscando a equidade como forma de cooperação e de motivação. De acordo com a professora pesquisadora que aplicou a prática, a atividade respeitou o tempo individual oportunizado ao aluno 
para buscar informação, experimentar —criar—, compartilhar com os colegas, reelaborar a informação e transformar em conhecimento próprio o que foi vivenciado no coletivo.

Concluise que as atividades pedagógicas com uso das tecnologias favorecem o acesso às informações de forma rápida, potencializando o processo de aprendizagem da produção textual, a aquisição e a compreensão do idioma. Os sistemas colaborativos mediados pela utilização dos smartphones como recursos digitais e enlace de atividades interativas desenvolvidas podem vir a favorecer o multiletramento e ampliar o conhecimento.

\section{Referências}

Castro, A.; Menezes, C. (2011). Aprendizagem colaborativa com suporte computacional. En M. Pimentel; H. Fuks (Ed.). Sistemas Colaborativos. (135-153). Estados Unidos: Elsevier.

Dos Santos, F. M. A. (2018) A produção de textos em ambientes digitais: possíveis caminhos para o ensino da escrita. Todas as Letras. São Paulo, 20(3), 196-211. DOI: https://doi. org/10.5935/1980-6914/letras.v20n3p196-211

Elicker, A. T. (2020a) Celular, aplicativos e plataformas: receita para potencializar os encontros a distância. Boas Práticas. Março/ TVEscola. Recuperado de https://bit.ly/3gfburl

Elicker, A. T. (2020b) Textos digitais multimodais de forma colaborativa entre os alunos. Base Nacional Comum Curricular. Recuperado de https://bit.ly/2KYpOFJ
Elicker, A. T.; Barbosa, D.N.F. (2020) Literacia digital: projeto pedagógico cooperativo. Pernambuco: Even3 Publicações. DOI: https://doi.org/10.29327/512424

Elicker, A. T.; de Mattos- Batistello, V. C.; Lorenz-Martins, R.; Bez, M. R. (2019). Produções Textuais em Espaços Digitais. Revista Virtu@lmente, 7(1),45-62. DOI: https://doi.org/10.21158/2357514x.v7.n1.2019.2321

Fuks, H.; Raposo, A.; Gerosa, M.A.; Pimentel, M.; Lucena, C.J.P. (2007). The 3C Collaboration Model. No N. Kock (Org.) The Encyclopedia of E-Collaboration. (637-644). Hershey, PA: Information Science Reference. DOI: https://doi. org/10.4018/978-1-59904-000-4.ch097

Gomes, R. (2017). Objetos De Aprendizagem E Novos Letramentos: Uma Análise Do Objeto Enem Wars. Revista De Estudos Acadêmicos De Letras, 10(1), 134-153.

Lemos, A.; Lévy, P. (2010). O Futuro Da Internet. São Paulo: Paulus.

Ministério Da Educação. (2018a). Base Nacional Comum Curricular. Brasília: Mec. Recuperado de https://bit.ly/37HAQPM

Ministério Da Educação. (2018b). Base Nacional Comum. A Educação É A Base. Brasília. S/D. Recuperado de https://bit. ly/3gd5JiK

Moreira, A; Porto, C. (2017). Educação No Ciberespaço Novas Configurações, Convergências E Conexões. Santo Tirso: EDUNIT/Whitebooks

Nicolaci da Costa, A. M.; Pimentel, M. (2011). Sistemas colaborativos para uma nova sociedade e um novo ser humano. No M. Pimentel; H. Fuks (Orgs.) Sistemas colaborativos. (3-15). Rio de Janeiro: Elsevier. 
Oliveira, D. (2014). A Produção De Texto No Ambiente Online De Aprendizagem Moodle: Relato De Experiência. Texto Livre: Linguagem E Tecnologia, 7(1),1-13. DOI: https://doi. org/10.17851/1983-3652.7.1.1-13

Palfrey, J; Gasser, U. (2011). Nascidos Na Era Digital. Entendendo A Primeira Geração De Nativos Digitais. Porto Alegre, Rs: Grupo A.

Pimentel, M.; Fuks, H. (2007). Sistemas Colaborativos. Rio de Janeiro: Elsevier.

Pozzo, M. I. (2020) Reflexiones y decisiones didácticas sobre prácticas de enseñanza virtual de escritura de tesis de postgrado. Revista de Educación, (19), 66-88.

Reis, A. R. S.; de Carvalho-Lima. S. (2019). Letramento digital: uma proposta de ensino em língua portuguesa na educação profissional. Mossoró, Brasil. Recuperado de https://bit. ly/2ljhF68

Rojo, R. (2013). (Org.). Escol@ Conect@D@: Os Multiletramentos E As Tics. São Paulo: Parábola.

Scherer-Bassani, P.; da Silva-Nunes, J. (2016). Ensinar E Aprender $\mathrm{Em} / \mathrm{Na}$ Rede: Diferentes Abordagens Teórico-práticas Do Conceito De Ambientes Pessoais De Aprendizagem. V Jornada De Atualização Em Informática Na Educação. V Congresso Brasileiro de Informática na Educação. Uberlândia, MG, Brasil, 24 a 27 de outubro.

Thiollent, M. (1988). Metodologia Da Pesquisa-ação. São Paulo: Cortez. 